\title{
Air Sampling: A Mini-denuder Sampling Device for Direct Desorption in an Inlet of a Gas Chromatograph for the Analyses of Airborne Gaseous Phase Pollutants and Airborne Particulate Phase Pollutants
}

\author{
Estefan van Vuuren ${ }^{\mathbb{D}}$ and Yvette Naudét ${ }^{(\mathbb{D})} \S$ \\ Department of Chemistry, University of Pretoria, Private Bag X20, Hatfield, 0028, South Africa.
}

Received 22 November 2018, revised 18 February 2019, accepted 18 February 2019.

\begin{abstract}
We introduce a compact mini-denuder air sampling device consisting of a regular gas chromatograph (GC) inlet liner for the simultaneous concentration of separate airborne gaseous and particulate phases in a single-step. Denuder materials are thermally desorbed in a regular inlet of a GC using routine equipment available in any chromatography laboratory. The simplicity of the technique makes it ideal for resource-poor laboratories.
\end{abstract}

KEYWORDS

Air sampling, gas chromatography, denuder, polydimethylsiloxane (PDMS), thermal desorption.

\section{Introduction}

Semi-volatile organic compounds are present in air, either adsorbed onto dust particles, or as free gas phase molecules. ${ }^{1}$ Diffusion denuder samplers are employed to sample particulate phase and gas phase air pollutants. ${ }^{1,2}$ Due to a difference in vapour and particle diffusivities diffusion denuders first separate the vapour phase to be retained on a sorptive surface from the particulate phase which passes through the denuder and is then collected on a downstream filter. ${ }^{1,2}$ Denuder materials are solvent-extracted or thermally desorbed in commercial thermal desorber systems for subsequent analyses.

Conventional diffusion denuders include annular, multicapillary or honeycomb designs that are coated with adsorbents such as Tenax or Florisil. ${ }^{1}$ However, the challenges associated with adsorbents together with thermal desorption are incomplete desorption, ${ }^{3}$ or that the temperatures required to fully desorb the sample to the GC column can be as high as $300^{\circ} \mathrm{C}$ to $350^{\circ} \mathrm{C}$ resulting in decomposition of compounds. Denuder fabrication procedures are usually complicated.

Ortner and Rohwer originally developed a polydimethylsiloxane (PDMS) multichannel trap for the analysis of semivolatile air pollutants. ${ }^{4}$ Sample concentration by means of PDMS performs well in combination with thermal desorption. ${ }^{3}$ Contrary to adsorptive trapping, PDMS is an absorbant and acts as a hydrophobic solvent for analytes. ${ }^{3}$ The PDMS multichannel trap was since utilized as a diffusion denuder for sampling of the insecticide DDT in contaminated indoor air and atmospheric polycyclic aromatic hydrocarbons (PAHs) in mines. ${ }^{1,2}$ In these studies denuder materials were constructed in commercial thermal desorber glass tubes for desorption in thermal desorber systems with cryogenics. However, expensive thermal desorber systems and cryogenics may not be readily available in resourcepoor laboratories. Motivated by economical restraints faced by laboratories in a developing country we designed a simple mini-denuder device consisting of a regular GC inlet liner. The

* To whom correspondence should be addressed.

E-mail: yvette.naude@up.ac.za denuder materials are made of a collection of PDMS (silicone rubber) tubelets arranged in parallel inside an inlet liner for collection of gaseous phase pollutants and a quartz fibre filter for the downstream collection of particulate phase pollutants for the simultaneous concentration of both phases in a single-step. The denuder materials are desorbed directly in an inlet of a GC without cryogenics. The GC inlet liner mini-denuder device is particularly well suited to resource-poor laboratories because routine chromatography equipment is used.

\section{Experimental}

\section{i. Chemicals and Materials}

For linear retention index determination an $n$-alkanes $\left(\mathrm{C}_{10}-\mathrm{C}_{28}\right)$ mixture was used (Merck, South Africa). Air sampling of domestic fires made with three types of briquettes consisting of recycled paper or recycled paper with a soft wax coating or a hard wax coating (Clearflame briquettes, Pretoria, South Africa) was done using the mini-denuder.

\section{ii. Mini-denuder and Air Sampling}

The mini-denuder was made up of two multichannel silicone rubber traps separated by a quartz fibre filter which was held in position by a Teflon sleeve (Fig. 1A). Twelve silicone elastomer medical grade tubes $(0.6 \mathrm{~mm}$ OD $\times 0.3 \mathrm{~mm}$ ID, SILTEC, Technical Products, Georgia, U.S.A.) were arranged in parallel inside a regular glass inlet liner, straight through type, $6.3 \mathrm{~mm}$ OD, suitable for an Agilent GC (Supelco, South Africa). The PDMS multichannel trap inside the inlet liner was $57 \mathrm{~mm}$ long. The PDMS traps consisted of $0.36 \pm 0.002 \mathrm{~g}$ silicone rubber and were prepared based on a technique described by Ortner and Rohwer. ${ }^{4}$ The trap had an analyte enrichment volume of $600 \mu \mathrm{L}$ PDMS. Quartz fibre filters of $6 \mathrm{~mm}$ in diameter were punched from Ederol Quartz Microfibre sheets $(0.43 \mathrm{~mm}$ thickness, pore size $0.3 \mu \mathrm{m}$, grade T293) from Munktell \& Filtrak GmbH Bärenstein, Germany.

Air samples were collected with a portable, battery operated 


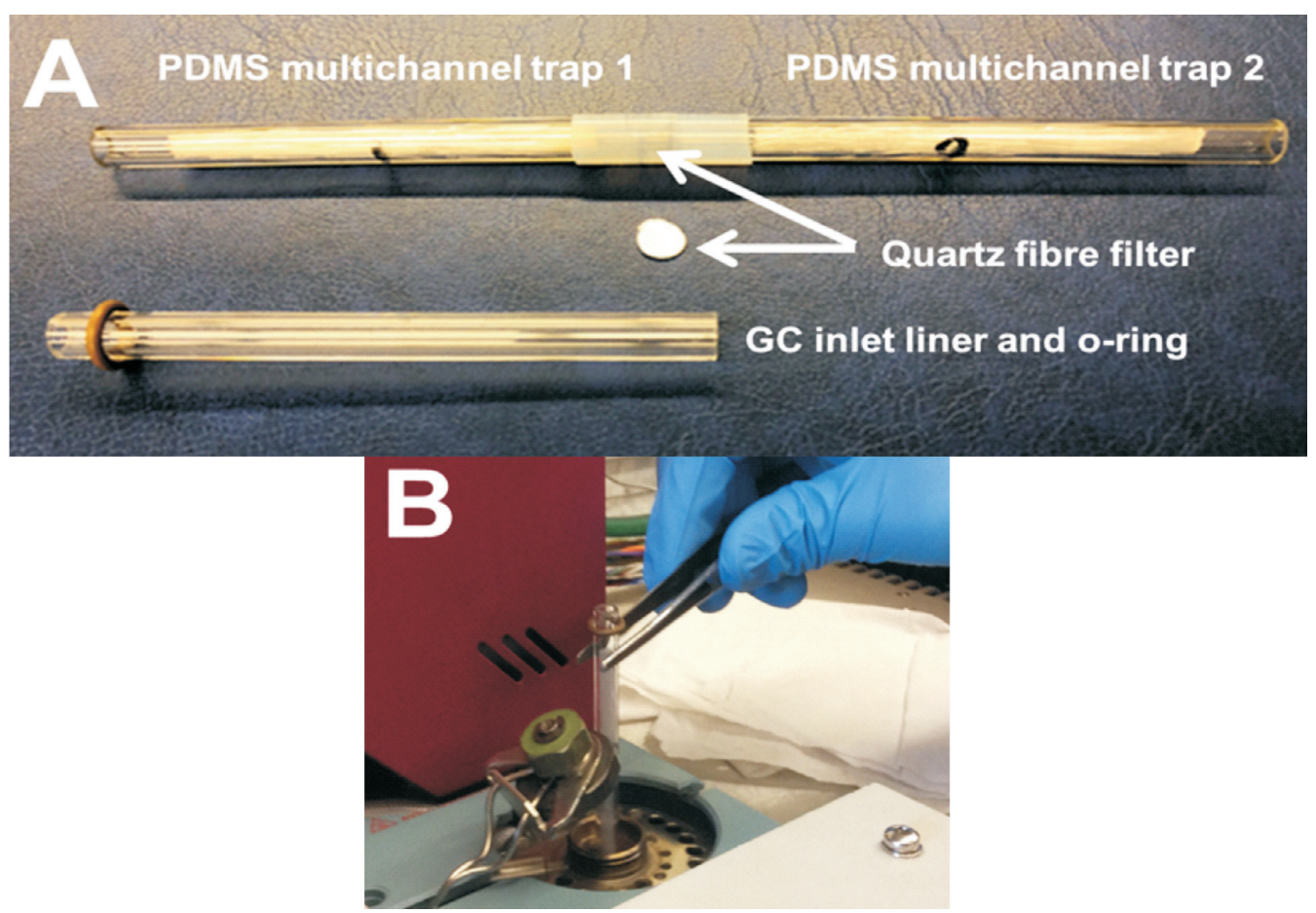

Figure 1 (A) A mini-denuder device consisting of two multichannel silicone rubber traps separated by a quartz fibre filter which is held in position by a Teflon sleeve. Twelve silicone rubber tubelets are arranged in parallel inside a regular glass inlet liner. The PDMS multichannel trap inside each inlet liner is $57 \mathrm{~mm}$ long. An empty GC inlet liner is shown for comparison. (B) Inserting a liner with a multichannel PDMS trap (or filter) into the inlet of a GC-MS for thermal desorption and analysis.

sampling pump (manufactured in-house). ${ }^{1}$ The pump was attached to the mini-denuder with Tygon tubing. Sampling was done for $20 \mathrm{~min}$ at a low flow rate of $\sim 85 \mathrm{~mL} \mathrm{~min}^{-1}$ to minimize/ prevent potential analyte breakthrough.

\section{iii. GC-MS}

Analyses were performed using a Hewlett Packard (HP) GC 1530A coupled to a HP 5973 mass selective detector (MSD) (Chemetrix, Johannesburg, South Africa). The same instrumental conditions were used for analyses of the multichannel traps (gas phase airborne pollutants) and for the quartz fibre filters (particulate phase airborne pollutants). GC separation was performed on a HP-5 $30 \mathrm{~m} \times 320 \mu \mathrm{m}$ ID $\times 0.25 \mu \mathrm{m}$ film thickness (Agilent, Chemetrix, South Africa) column, the carrier gas (helium) velocity was set at $44 \mathrm{~cm} / \mathrm{s}(1.4 \mathrm{~mL} / \mathrm{min})$ with a column head pressure of $1 \mathrm{psi}$ in the constant flow mode. The GC oven temperature programme was $30{ }^{\circ} \mathrm{C}(10 \mathrm{~min})$ at $10{ }^{\circ} \mathrm{C} \mathrm{min}^{-1}$ to $300^{\circ} \mathrm{C}$ (1 min). The GC run time was $37 \mathrm{~min}$. The GC-MS transfer line was at $300{ }^{\circ} \mathrm{C}$, the source $(\mathrm{EI}+)$ temperature $230{ }^{\circ} \mathrm{C}$, the MS quadrupole temperature $150^{\circ} \mathrm{C}$, the ionization energy $70 \mathrm{eV}$ and the electron multiplier (EM) was set at $1750 \mathrm{~V}$. Chromatograms were recorded in the full scan mode at $40-450$ atomic mass units. Tentative identification of compounds detected from air sampling was performed by comparison of mass spectra to that of the Wiley mass spectral library. Analytes with a mass spectral match of $80 \%$ or greater are reported. Experimental linear retention indices were calculated and compared to those in the literature to confirm these tentative identifications.

\section{iv. Thermal Desorption of the Mini-denuder Device Directly in the Inlet of a GC-MS}

The inlet of the GC-MS was set at $250^{\circ} \mathrm{C}$ in the split mode (split 100:1). The gas flow was shut off prior to opening the inlet of the GC, the inlet liner was removed from the inlet and replaced with an inlet liner containing a multichannel trap or a quartz fibre filter (Fig. 1B). The inlet was closed, the gas flow was restored, and the run started.

The portable mini-denuder sampler contained two PDMS multichannel silicone rubber traps each inside an inlet liner of a GC which are connected in series and are separated by a quartz fibre filter (Fig. 1A). The PDMS acts as an absorbent for gaseous semivolatile analytes and the filter collects the particle phase analytes downstream from the PDMS multichannel trap. Mini-denuder materials (PDMS multichannel trap or filter) were desorbed in a regular GC inlet of a GC-MSD (Fig. 1B). Inlet liners containing adsorbents, e.g. Tenax, are commercially available. However, diffusion denuders require an open-type arrangement to allow particles to pass through. Also, as discussed earlier, there are limitations associated with thermal desorption and adsorbents.

Organic compounds from domestic fires were successfully desorbed from a PDMS multichannel trap (vapour phase) and a quartz microfibre filter (particulate phase) in the inlet of a GC without the use of cryogenics or inlet modifications (Fig. 2). The second back-up trap after the filter was analyzed to check for any breakthrough of analytes and none was detected (Fig. 3).

Figure 4 is a comparison of the gaseous phase airborne pollutants on the PDMS multichannel trap with the particulate phase airborne pollutants on the filter after a single-step, simultaneous sampling of both phases from domestic fires using briquettes made of recycled paper, or recycled paper with soft wax or hard wax coatings. Differentiation between the two phases, and as well as between the three fuel types, was achieved. As is to be expected of the particular fuel-type used in the making of the domestic fires, alkanes were present in the air samples. Here, the mini-denuder device was utilized for qualitative analyses. However, the device can easily be applied quantitatively by spiking the denuder materials with known concentrations of chemical standards of interest for the quantification of analytes in air samples. ${ }^{1,2}$ 


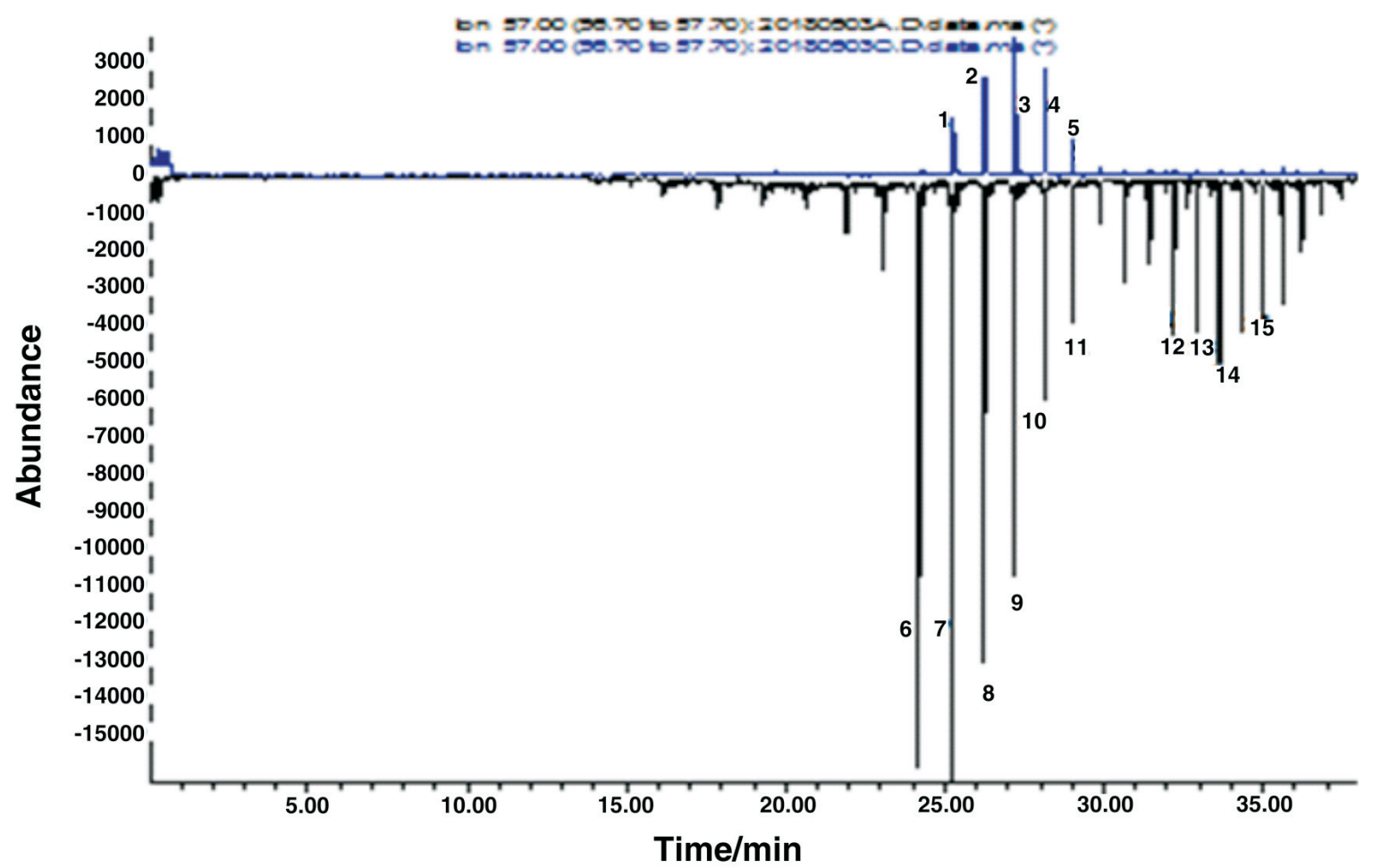

Figure 2 Reconstructed ion chromatograms $(57 \mathrm{~m} / \mathrm{z}$ ) of a desorbed quartz microfibre filter (particulate phase, top) and a multichannel PDMS trap (vapour phase, bottom) in a regular inlet of a GC-MS without inlet modification. Compounds detected in the two separate phases from a domestic fire using briquettes made of recycled paper with a soft wax coating were particulate phase compounds from filter (top): ${ }^{1}$ Heptadecane 2 -methyl, ${ }^{2}$ Nonadecane, ${ }^{3}$ Eicosane, ${ }^{4}$ Heneicosane, ${ }^{5}$ Tricosane 2-methyl, and gaseous phase compounds from multichannel trap (bottom): ${ }^{6} \mathrm{Heptadecane}$, ${ }^{7}$ Octadecane, ${ }^{8}$ Nonadecane, ${ }^{9}$ Eicosane, ${ }^{10}$ Heneicosane, ${ }^{11}$ Docosane, ${ }^{12}$ Pentacosane, ${ }^{13}$ Hexacosane, ${ }^{14}$ Heptacosane, ${ }^{15}$ Octacosane. Unlabelled peaks are siloxanes or compounds with a mass spectral match $<80 \%$.

A simple mini-denuder using a regular GC inlet liner for the single-step, simultaneous sampling of airborne pollutants in both the gaseous and particle phases as discrete fractions was demonstrated. The denuder materials (PDMS tubelets and a quartz fibre filter) were easily desorbed directly in a regular inlet of a GC-MSD without the need for cryogenics or inlet modifications. Thermal desorption was achieved with routine equipment available in any chromatography laboratory. The simplic- ity of the technique makes it ideal for resource-poor laboratories.

\section{Acknowledgements}

Egmont Rohwer's original denuder designed for a commercial thermal desorber system was the inspiration for developing the inlet liner mini-denuder air sampling device. David Masemula is thanked for assembling the mini-denuders and Niel Malan for providing Clearflame briquettes.

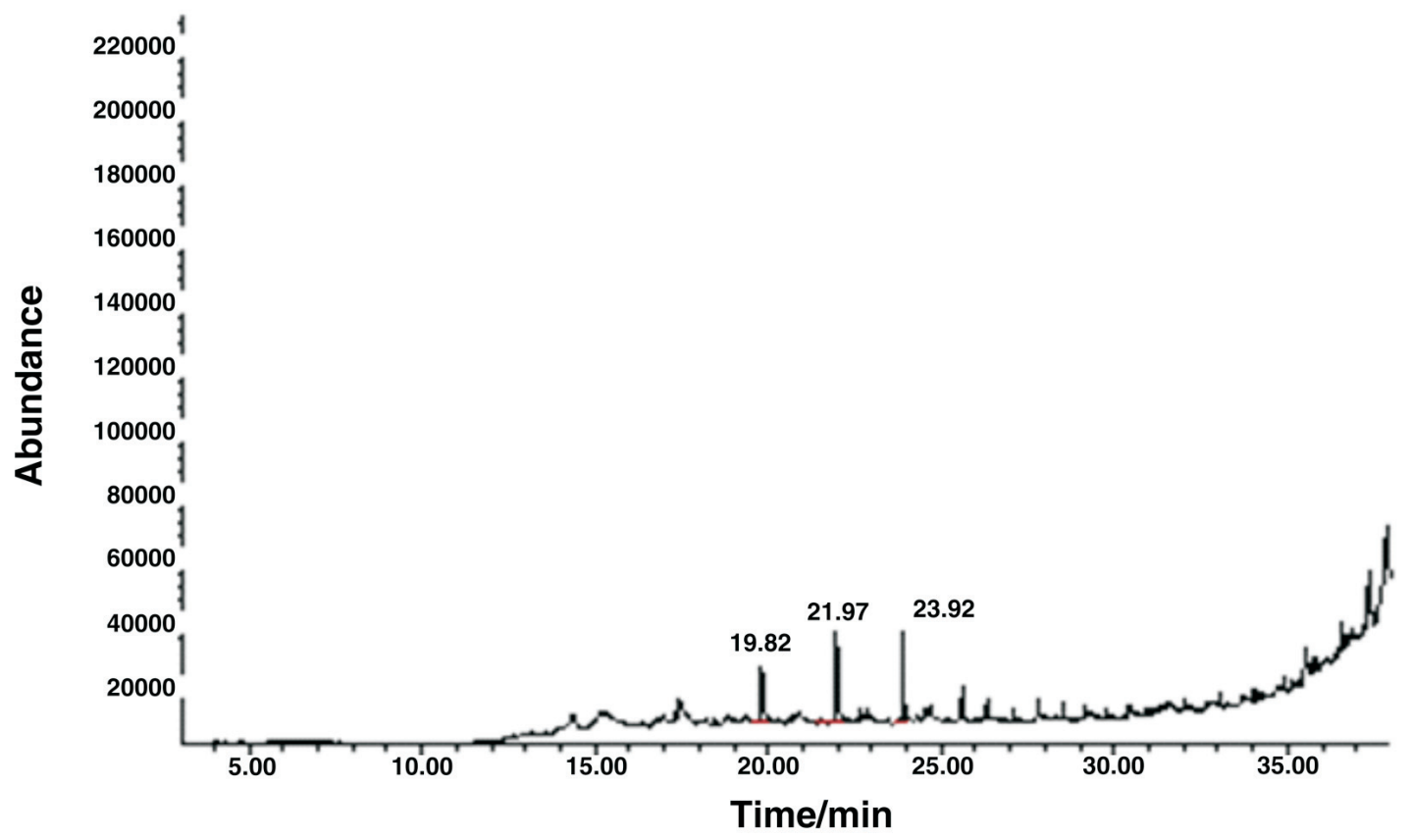

Figure 3 Chromatogram of a desorbed multichannel PDMS back-up trap (second trap after the filter) in a regular inlet of a GC-MS. Breakthrough of analytes did not occur (the three peaks are siloxanes from the silicone rubber sorptive material of the trap). 


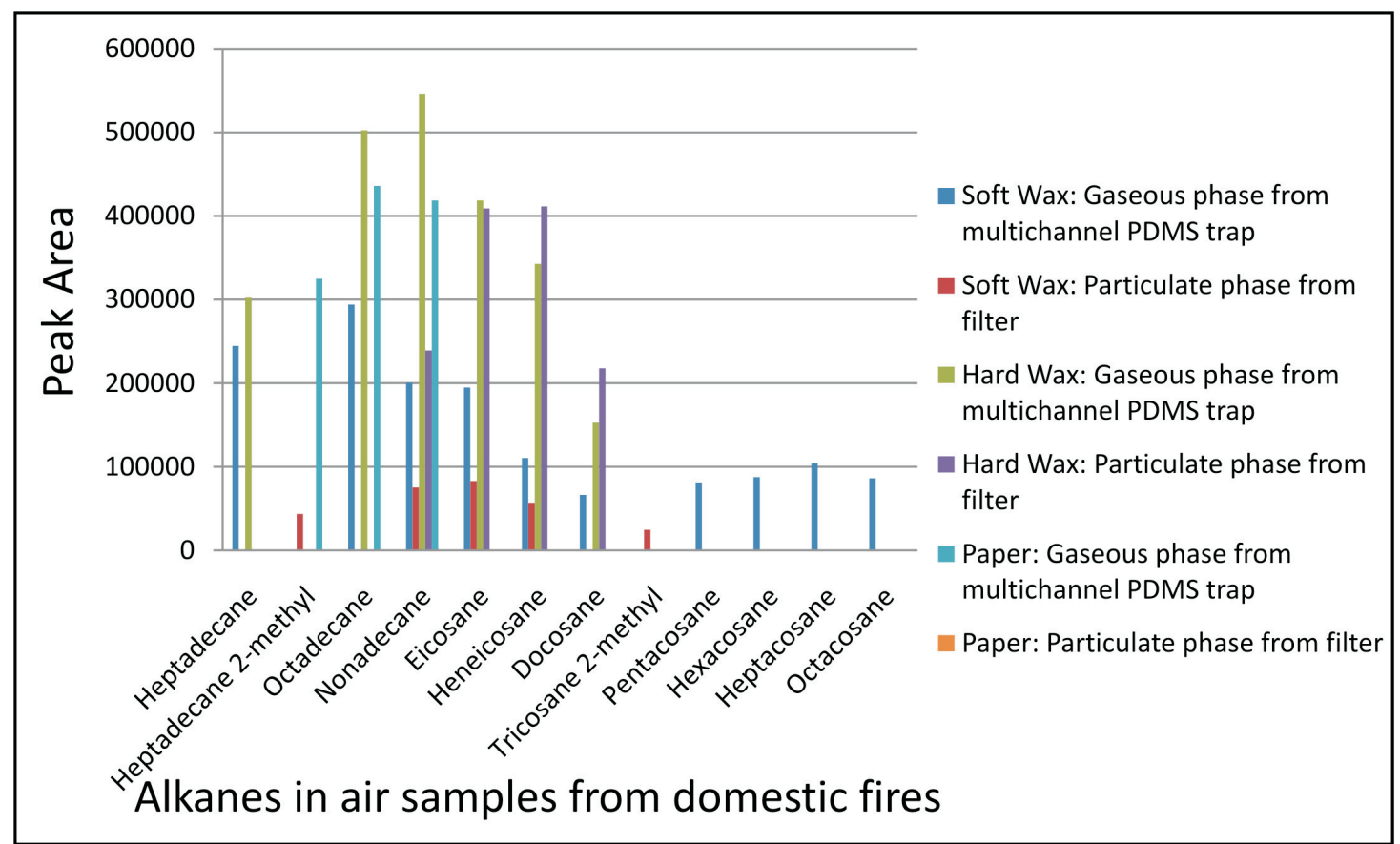

Figure 4 Airborne pollutants from three domestic fires (using briquettes made of recycled paper, or recycled paper with soft wax or hard wax coatings) sampled with a mini-denuder: single-step gaseous phase and particulate phase sampling yields two separate fractions. Particulate phase compounds were not present for the paper fire. Analytes with a mass spectral match of $80 \%$ or greater are reported.

\section{${ }^{8}$ ORCID iDs}

E. van Vuuren:

Y. Naudé:

orcid.org/0000-0003-3534-5298

orcid.org/0000-0002-5447-4389

\section{References}

1 Y. Naudé and E.R. Rohwer, Novel method for determining DDT in vapour and particulate phases within contaminated indoor air in a malaria area of South Africa. Anal Chim Acta., 2012, 730, 112-119.

2 G. Geldenhuys, E.R. Rohwer, Y. Naudé and P.B.C Forbes, Monitoring of atmospheric gaseous and particulate polycyclic aromatic hydrocarbons in South African platinum mines utilising portable denuder sampling with analysis by thermal desorption-comprehensive gas chromatography-mass spectrometry. J. Chromatogr A., 2015, 1380, $17-28$.

3 E. Baltussen, C.A. Cramers and P.J.F. Sandra, Sorptive sample preparation - A review. Anal. Bioanal. Chem,. 2002, 373(1-2), 3-22.

4 E.K. Ortner and E.R. Rohwer, Trace analysis of semi-volatile organic air pollutants using thick film silicone rubber traps with capillary gas chromatography. J. High Res. Chromatogr., 1996, 19, 339-343. 